\title{
The axial compression test and research on concrete prism specimens confined by corroded stirrups
}

\author{
Li Qiang Guan Xiao Xiao Qianhui Chen Shaojie \\ (Xi'an University of Science and Technology,Xi'an 710054,China) \\ 47961419@qq.com 86484869@qq.com 28263835@qq.com 2060522577@qq.com
}

\begin{abstract}
Keywords:Corroded stirrups; Prism specimens; Tress-strain curve; Constraint performance; Degradation mechanism

Abstract:Stirrups corrosion lead to degradation of ductility of concrete columns, the damage would transform from ductility to fragility, even to sudden destruction. In order to avoid concrete structure clasping because of the impact of earthquake and shocking, the mechanical property research of concrete columns confined with corroded stirrups is urgently needed. This paper mainly through axial compression test of the corroded stirrups confined prism concrete,study the different rate of corroded stirrups. The stirrups characteristic value and the damage protective layer, which influence the failure modes of concrete prism specimens,then do the analysis of the impact of various factors on the concrete confined with corroded stirrups stress-strain curve and its parameters, finally summarize the corrosion degradation mechanism of corroded stirrups concrete constraints.
\end{abstract}

\section{Introduction}

Stirrups not merely be a part of reinforcement cage of R. C. members, but also provide transverse constraints for both the core zone concrete and transverse reinforcement, which improved the strength and the ductility of concrete members, especially the ductility improved obviously. However, the recent engineering investigations show that when concrete carbonation reaches to the surface of stirrups, the stirrups will be rusted firstly because of its small diameter and thin concrete cover, and the corroded degree of stirrups is more serious than the transverse reinforcement ${ }^{[1-2]}$, particularly in the transition part of the transverse reinforcement and stirrup. Sometimes the amount of longitudinal steel corrosion is only $5 \sim 10 \%$, but the amount of stirrups corrosion is quite large, even rust off ${ }^{[3]}$. The corrosion of stirrups not only cuts down its cross sectional area and strength, but also causes transverse constraints of the core area concrete and transverse reinforcement diminishing even losing, which lead the ductility of reinforced concrete members degenerated ${ }^{[4-6]}$. The failure forms are changed from ductile failure to brittle failure, even cause abrupt failure. Currently, the research on the degradation of mechanical properties of concrete columns confined with corroded stirrups is almost blank at home and abroad, so it is an urgent problem to carry on this research. In this paper, concrete prism specimens get from electrochemical corrosion test are tested by axial compression experiment, in order to research the laws of the degradation of mechanical properties of concrete columns confined with corroded stirrups.

\section{Experiment Overview}

\section{Experiment Design}

57 concrete prism specimens were designed, whose stirrups are designed of two-leg square stirrups which is weakest to constrain the constraint concrete specimens. Designed 51 concrete prism specimens with corroded stirrups, and 3 non-corrosion concrete prism specimens and 3 concrete prism specimens which do not set stirrups to make comparison. The section size of concrete specimens is $150 \times 150 \times 450 \mathrm{~mm}$, and $4 \mathrm{HRB} 335$ transverse reinforcement which diameter is $12 \mathrm{~mm}$ set. Further details are provided in Table 1.

Material performance

The design strength of concrete specimens is $\mathrm{C} 25$, and the basic performance is shown in Table 2 . The transverse reinforcements of specimens use HRB335 grade steel, and stirrups use HPB235 grade steel. The basic mechanical performance of all specimens is shown in Table 3 . 


\section{Experiment preparation}

The text specimens get from the concrete prism specimens which are corroded by the accelerated corrosion test ${ }^{[7,8]}$, the test is based on corrosion electrochemical method. In the process of electrochemical accelerated corrosion test, the specimens are always soaked in the $\mathrm{NaCl}$ solutions, and the bottom of some concrete specimens is serious damaged. Use epoxy repair mortar to mend the specimens before axial loading test. To avoid axial loading test become invalid by the damage to the bottom of the specimens, all bottom of specimens are consolidated by pasting CFRP, the width of the CFRP is only $60 \mathrm{~mm}$ in order to ensure the reinforce measures have no effect on the performance of the specimens.

Reference to the literature ${ }^{[10-12]}$, this experiment uses microprocessor control hydraulic servo testing machine.

\section{Stirrup corrosion rate of specimens}

The numerical corrosion rate is the average rate of stirrup corrosion of 3 specimens in each group. The numerical corrosion rate of all specimens is shown in Table 4.

\section{Loading mechanism and test data collection}

The experiment loading adopt the mechanism with uniform speed displacement control. We take $0.3 \mathrm{~mm} / \mathrm{min}$ as displacement velocity, reference to the former experience and result of field test, because of corrosion of stirrups, corrosion cracking of concrete cover and degradation of bond behavior of steel bars, also appoint the finishing time is at the load lower than the peak load of $500 \mathrm{kN}$.

The axial load and axial displacement are automatically collected intervals of 0.5 seconds by the computers which are connected with pressure machine. The strain of stirrups and lateral strain of concrete are manual collected by the SDY2206 programmable static resistance strain gauge. The collecting rate of ascending segment data is controlled by load increment, the collecting rate of descending segment data is controlled by reaction rate of acquisition system.
Table 1 Concrete prism specimens

\begin{tabular}{|c|c|c|c|c|}
\hline specimens & $\begin{array}{l}\text { Stirrups } \\
/ \mathrm{mm}\end{array}$ & $\begin{array}{l}\text { Protective } \\
\text { cover } / \mathrm{mm}\end{array}$ & $\begin{array}{c}\text { Characteristic } \\
\text { value }\end{array}$ & Number \\
\hline A0 & \multirow{5}{*}{ Ф6@60 } & \multirow{5}{*}{12} & \multirow{5}{*}{0.2518} & 3 \\
\hline $\mathrm{A} 1$ & & & & 3 \\
\hline A2 & & & & 3 \\
\hline A3 & & & & 3 \\
\hline A4 & & & & 3 \\
\hline B1 & \multirow{4}{*}{$\begin{array}{c}\Phi 8 @ 10 \\
8\end{array}$} & \multirow{4}{*}{12} & \multirow{4}{*}{0.2518} & 3 \\
\hline B2 & & & & 3 \\
\hline B3 & & & & 3 \\
\hline B4 & & & & 3 \\
\hline $\mathrm{C} 2$ & \multirow{3}{*}{ Ф6@60 } & \multirow{3}{*}{12} & \multirow{3}{*}{0.1889} & 3 \\
\hline $\mathrm{C} 3$ & & & & 3 \\
\hline $\mathrm{C} 4$ & & & & 3 \\
\hline D2 & \multirow{3}{*}{ Ф6@60 } & \multirow{3}{*}{18} & \multirow{3}{*}{0.2638} & 3 \\
\hline D3 & & & & 3 \\
\hline D4 & & & & 3 \\
\hline E2 & \multirow{3}{*}{ Ф6@60 } & \multirow{3}{*}{25} & \multirow{3}{*}{0.2793} & 3 \\
\hline E3 & & & & 3 \\
\hline E4 & & & & 3 \\
\hline F0 & - & - & 0 & 3 \\
\hline
\end{tabular}

Table 2 Fundamental properties of concrete and blocks

\begin{tabular}{cccccc}
\hline $\begin{array}{c}\text { Material } \\
\text { types }\end{array}$ & $\begin{array}{c}\text { Bulk density } \\
/ \mathrm{kN} / \mathrm{m}^{3}\end{array}$ & $\begin{array}{c}\text { Compressive strength } \\
/ \mathrm{MPa}\end{array}$ & $\begin{array}{c}\text { Elastic modulus } \\
/ \mathrm{MPa}\end{array}$ \\
\hline C25 & 33.85 & 50.3 & $3.0 \times 10^{4}$ \\
\hline \multicolumn{6}{c}{ Table 3 Basic mechanical properties of reinforcement } \\
\hline \multirow{2}{*}{ Grade } & Diameter & $\begin{array}{c}\text { Yield } \\
\text { strength }\end{array}$ & $\begin{array}{c}\text { Ultimate } \\
\text { strength }\end{array}$ & $\begin{array}{c}\text { Elastic } \\
\text { modulus }\end{array}$ & Elongation \\
\hline HPB235 & $6 \mathrm{~mm}$ & $285 \mathrm{MPa}$ & $480 \mathrm{MPa}$ & $2.01 \times 10^{5}$ & $26.2 \%$ \\
HPB235 & $8 \mathrm{~mm}$ & $292 \mathrm{MPa}$ & $515 \mathrm{MPa}$ & $2.19 \times 10^{5}$ & $25.6 \%$ \\
HRB335 & $12 \mathrm{~mm}$ & $370 \mathrm{MPa}$ & $521 \mathrm{MPa}$ & $1.79 \times 10^{5}$ & $18.5 \%$ \\
\hline
\end{tabular}

Table 4 Stirrup corrosion rate of specimens

\begin{tabular}{cccccc}
\hline Component & $\delta(\%)$ & $\delta_{\mathrm{s}}(\%)$ & Component & $\delta(\%)$ & $\delta_{\mathrm{s}}(\%)$ \\
\hline A0 & 0 & 0 & $\mathrm{~A} 1$ & 14.00 & 18.50 \\
$\mathrm{~A} 2$ & 20.79 & 33.59 & $\mathrm{~A} 3$ & 25.09 & 55.95 \\
$\mathrm{~A} 4$ & 33.25 & 69.14 & $\mathrm{~B} 1$ & 18.92 & 44.49 \\
$\mathrm{~B} 2$ & 24.47 & 47.71 & $\mathrm{~B} 3$ & 29.23 & 56.08 \\
B4 & 32.04 & 69.72 & $\mathrm{C} 1$ & 15.82 & 25.42 \\
C2 & 20.96 & 34.01 & $\mathrm{C} 3$ & 27.76 & 48.31 \\
D1 & 20.68 & 28.97 & $\mathrm{D} 2$ & 22.75 & 41.04 \\
D3 & 19.85 & 46.00 & E1 & 19.48 & 25.75 \\
E2 & 25.55 & 36.72 & E3 & 21.52 & 38.01 \\
\hline
\end{tabular}

Note: $\delta$ is the average weight loss rate, $\delta$ s is the maximum weight loss rate.

\section{Analysis of experimental phenomena}

\section{Failure process and failure mode of specimens}

The specimens A0, whose stirrups has no corrosion have experienced the process with micro-cracks generation, growth and perforation, concrete cover spall, inclined section formation to ultimate loaded failure. The specimens F0 without stirrups have experienced the process with micro-cracks generation, growth and perforation, to loaded failure. When the load achieves 50 90\% of peak load, 
specimens surface appears cracks, and grow up quickly. The main cracks are at the corner of specimens. After the surface cracked concrete cleaned, there is serious damage take place in the core area of concrete, and the transverse reinforcement buckling obviously. Figure 1 shows failure modes of non-corrosion stirrups and without stirrups specimens.

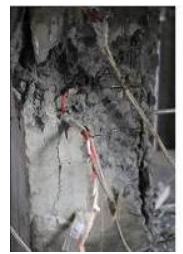

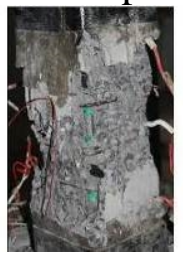

(a)

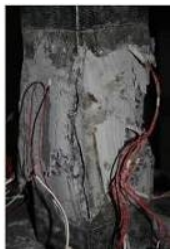

Fig.1 Failure modes of un-corroded specimens

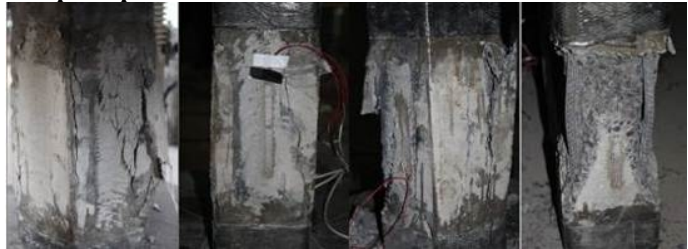

(b)

Because the specimens A1 have a smaller maximum mass loss rate, the concrete cover has no obviously corrosion crack, the failure process and failure mode are the same as the specimens A0, but owing to the tiny holes around of stirrups crammed by liquid corrosion products, the time of failure process is longer than specimens A1, the crack period of concrete cover is delayed, and the cracks appeared once grow more faster. Due to the other specimens confined by corroded stirrups have bigger weight loss, there are corrosion cracks or space existing in the surface of concrete cover and the surface between concrete cover and the core concrete. During the initial period of compression, the compressive stress grows slowly, but the vertical displacement is more quickly, which shows that the original cracks are healed during this period. In the subsequent loading stage, the load and vertical displacement are developing rapidly, and cracks don't develop obviously, but when the load reach $60 \sim 70 \%$ of its peak value of specimens, the original corrosion cracks began to develop, and the cracks developing time are advanced and developing rate are accelerated with the increasing extent of stirrups corrosion. As the original cracks developing, new vertical cracks are generated at the corner of specimens, and new cracks and original cracks linked up quickly, and the binding surface between concrete cover and core concrete peeled off immediately. When exceeded peak load, the load declined rapidly, and the vertical displacement increased dramatically. When the vertical load decline to about $40 \%$ of its peak load of every specimen, the stirrups broke in corner, the transverse reinforcement are buckling, and the bearing capacity of specimen has declined dramatically, the core concrete are crushed meanwhile.

Although the original corrosion cracks are growing slowly with the new cracks appearing constantly in the axial compression test, the ultimate compressive damaged oblique section are developed basing on the original cracks. The failure features are changing along with the corrosion rate increasing, the damage degree of core concrete is gradually increasing, the oblique section is obvious gradually at the same time, and the period of failure process is gradually shortening when exceeding the peak load, which means that the ductility of damaged specimens is getting smaller, the damage mode transforms to brittle failure even. In addition, there are some affects come from the spacing of stirrups and concrete cover, the bigger stirrups spacing and the thicker concrete cover, the damage of core concrete more serious. The abruption of corroded stirrups always appears in the corner. Group A $\sim$ E failure modes of corrosion specimens are showed in Figure 2.

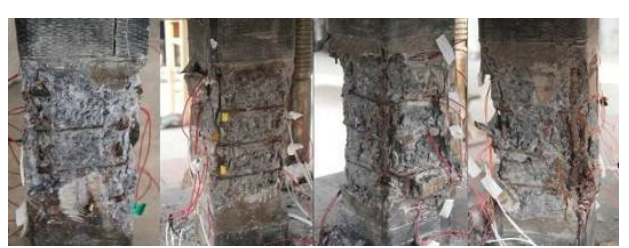

(a) $\mathrm{A} 1 \sim \mathrm{A} 4$
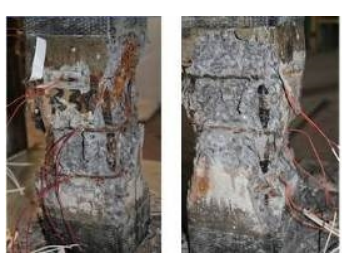

(c) $\mathrm{C} 2 \sim \mathrm{C} 4$

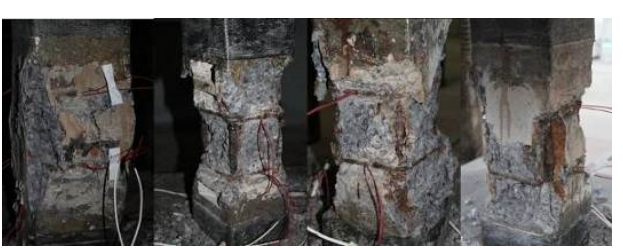

(b) $\mathrm{B} 1 \sim \mathrm{B} 4$
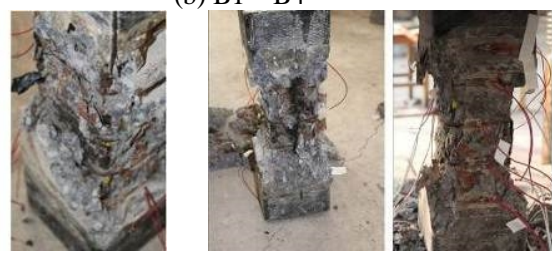

(e) $\mathrm{E} 1 \sim \mathrm{E} 4$
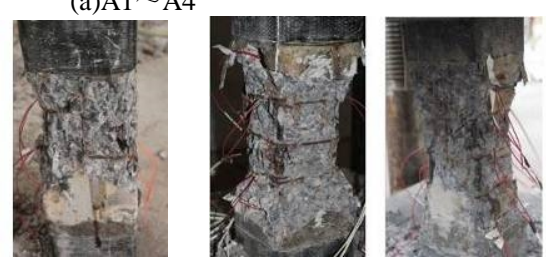

(d) $\mathrm{D} 2 \sim \mathrm{D} 4$

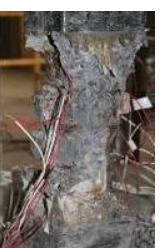

Fig.2 Group A E failure modes of corroded specimens 


\section{Concrete damage analysis}

Corrosion expansion caused the concrete damage, which includes the crack of specimen surface and the corrosion accumulation at the interface of concrete cover and the core area caused concrete cover stripping gradually, which results in the bearing capacity contribution of concrete cover decreases gradually, amounting to reducing the effective cross sectional area of specimens. Total accumulation of the corrosion has a direct relationship with the stirrups average corrosion rate and the ratio of concrete cover thickness and the stirrups diameter $(\mathrm{a} / \mathrm{d})$.

For the specimens A, B, C with smaller concrete cover, the values of a/d are 2, 1.5, 2, and the overall uneven corrosion degree of stirrups is larger, the stirrups corrosion accumulation and the difference of distribution both increase obviously accompanied with the maximum weight loss rate of stirrups increasing. When the average corrosion rate is below 20\% (slight corrosion), the amount of corrosion accumulate rarely, and only exists in the corner of specimens and near the stirrups sections. when the average corrosion rate ranged from 20 to $30 \%$ (moderate corrosion), corrosion accumulation increases, and not only exists in the corner of specimens and near the stirrups sections, but also exists in the interface of concrete cover and the core area, but mainly near the stirrups. When the average corrosion rate is more than $30 \%$ (severe corrosion), the accumulation of corrosion is much larger, which are obviously layer distribution throughout the interface of concrete cover and the core concrete.

For the specimens D, E with the bigger concrete cover, the values of a/d are 3 and 4.17, and the overall uneven corrosion degree of stirrups is small, the difference of corrosion accumulation and distribution is small. When the average corrosion rate is below 20\% (slight corrosion), the amount of corrosion accumulate rarely, and only exists in the corner of specimen and near the stirrups sections. When the average corrosion rate is more than $30 \%$ (severe corrosion), the accumulation of corrosion is much larger, which are obviously layer distribution throughout the concrete layer and the core concrete protection interface.

During The Compression test, the cracking process of lighter corrosion specimens are basically the same as un-corroded specimens, but crack development speed is slower than un-corroded specimens, which illustrates that the stirrups corrosion doesn't caused significant damages to the concrete cover, and since corrosion filled the concrete pore near the stirrups, the stiffness of specimens increased slightly. For moderate and severe corrosion specimens, the cracking time is earlier than that of the un-corroded specimens and crack development speed is rapider than un-corroded specimens, which suggests that the stirrups corrosion caused significant damages to the concrete cover, and this trend is gradually obvious with the increase of the maximum corrosion rate.

\section{Text result analysis}

\section{Concrete confined with corroded stirrups stress-strain curve}

This paper analysis the stress-strain curve of concrete confined with corroded stirrups ${ }^{[10,11]}$, the concrete cover which contributes to the bearing capacity of the specimens are out of consideration, the research object is the core zone of concrete stress-strain curve; when analysis the core zone of concrete stress-strain curve, the longitudinal steel bearing vertical load is out of consideration.

According to the experimental data and the average of curve diagram, A E sets of concrete stress-strain curve are showed in figure 3, vertical and horizontal coordinates respectively express the concrete stress which is according to longitudinal strain of the reduced concrete core area.
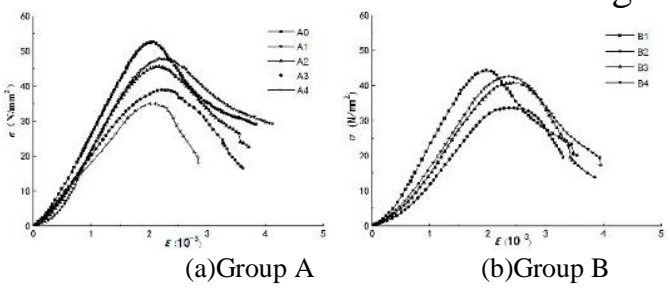

(b)Group B

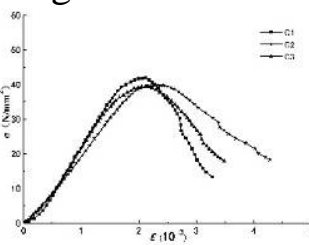

(c)Group C

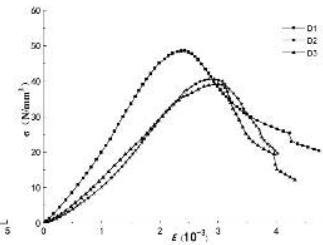

(d)Group D

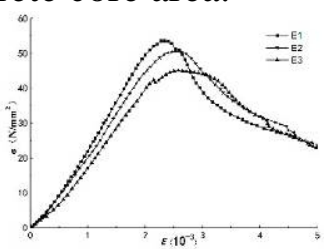

(e)Group E

Fig.3 The tress-strain curves of constrained concrete

According to the figure 3, stress-strain curve of concrete confined with corroded stirrups mainly exists the following features: At the ascending segment, the stress-strain curve of concrete confined 
with corroded stirrups are basely the same, overall performance for convex curve, with load increasing, stiffness is gradually reduce; with corrosion rate of stirrups increasing, stress-strain curve is on the slope decreases; Stress-strain curve segment of the initial segment is slightly different, in the case of stress changes little, the strain develops faster, the curve slightly concave. With the increasing rate of stirrups weight loss, the peak load of stress-strain curve of concrete confined with corroded stirrups is decreasing gradually, the peak strain is increasing gradually. At the descending segment, the stress-strain curve of concrete confined with corroded stirrups are significantly different, the specific performance are as follows: In good condition group, descending segment of the curve declines relatively smooth, descending segment is longer, and have obvious horizontal extension; It has lightly corrosion in group A1, descending segment is lower intensity and has obvious horizontal extension, and the stress and strain are not significantly reduced. In the late compressive period, the deformation performances better slight than the intact specimens, this may due to corroded products filling the pores between steel and concrete, improving the performance of the bond between steel bar and reinforced concrete after slight corrosion of steels; Except relative serious corroded group E, with the increase of stirrups corrosion degree, the stress-strain curve of falling slope gradually decreases, and gradually become steep, horizontal extension except slight corrosion is still evident when other stirrups corrosion degree of stress-strain curve of the specimens larger decline period of horizontal extension is not obvious, stirrups corrosion caused by specimen stiffness is decreased obviously, its ductility decreased significantly, the damage form of specimens from the ductile fracture to brittle failure gradually; As a result of group E has bigger initial stirrups characteristic value and bigger thickness of the concrete cover, while the specimen stiffness is decreasing as stirrups maximum weight loss rate increasing, but decreasing degree is smaller, descending segment of all specimens stress-strain curve is still has a long horizontal extension, suggesting that the specimen in stirrups maximum weight loss rate of the test still has good ductility.

\section{Influence factors analysis}

(1) Stirrups corrosion rate

Figure 3 reflects the stirrups corrosion rate of concrete confined with corroded stirrups stress-strain curve.

(2) Stirrups characteristic value

Figure 4 shows the stirrups characteristic value to the stress-strain curve of concrete confined with corroded stirrups.

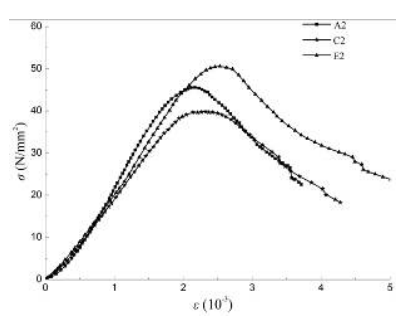

(a)

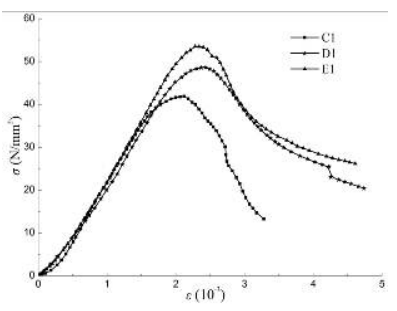

(b)

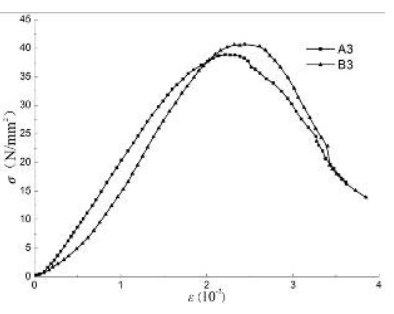

(c)

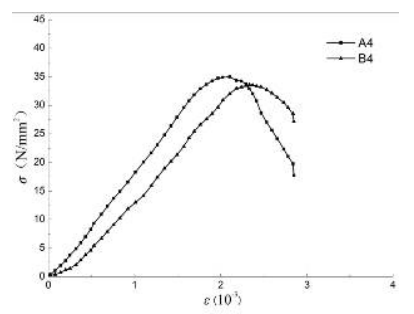

(d)

Fig.4 The influence of stirrups characteristic values to the tress-strain curve

From the figure 5 (a), (b), it can be seen that when the stirrups corrosion rate is nearly, the stress-strain curve ascending segments of concrete confined with corroded stirrups are almost the same. It is because early in the axial compression test, stirrups stress is lesser, stirrups on the restraint of concrete has not fully embodies; The peak load of stress-strain curve of stirrups confined concrete is increasing with the stirrups characteristic value of confined concrete, it is the same with stirrups characteristic value to the intact stress-strain curve of stirrups confined concrete specimens; The greater stirrups characteristic value of confined concrete is, stress-strain curve of concrete confined with corroded stirrups goes down flatly, it means that the ductility of concrete confined with corroded stirrups goes up with the increasing stirrups characteristic value.

By the figure 5 (c), (d), it can be seen that when stirrups corrosion rate is equal, stirrups characteristic value of the same confined concrete stress-strain curve is different, mainly showing 
that the stress-strain curve ascending segment and descending segment are different; Difference of ascending segment associated with stirrups corrosion which damaging concrete cover, the greater damage degree of concrete cover, stress-strain curve segment on the beginning of the concave phenomenon is more obvious, which can lead to rising curve line segment of basically the same slope and the peak strain differences; Decline differences mainly related with the stirrups spacing, the greater the stirrups spacing, the concrete constraint ability weak, the steep decline.

(3) The stirrups spacing

Concrete confined with corroded stirrups stress-strain curve ascending segment changes the slope $\lambda$ of the straight line as shown in figure 5. Stirrups spacing is $60 \mathrm{~mm}$ of A, D, E group of slope change are smaller, and put up basic linear change; Stirrups spacing is $108 \mathrm{~mm}$ and $80 \mathrm{~mm}$ of respectively B and C group of

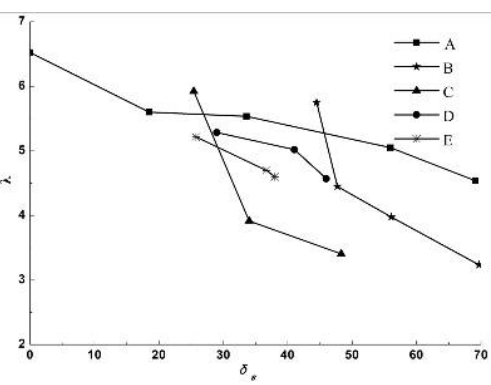

Fig.5 Slope changes of the rising of the tress-strain curve slope change are bigger, put on a nonlinear variation, but due to the hoop characteristic value of group $\mathrm{C}$ is bigger than group $\mathrm{B}$, the degree of slope changes is less than group $\mathrm{C}$.

\section{Conclusion}

By contrast the axial compression test results, concrete confined with corroded stirrups prism specimens and non-corrosion concrete prism specimens are discussed. Researching about damaging process, damaging feature, the damage of concrete cover and the stress-strain curve and influence factors of corroded stirrups specimens, the conclusions are shown as follows:

(1) The greater degree of corroded stirrups of concrete specimens whose failure is a progress of micro cracks producing and developing, it is the same as non-corroded stirrups specimen, but the period is longer, the rate of cracks developing is slower. The greater degree of corroded stirrups of concrete specimens whose failure is a progress of corrosive cracks producing and developing, and the failure section are formed form the original corrosive cracks. As the corrosion rate of stirrups increasing, the failure degree of core concrete is getting higher, and the oblique failure feature are gradually changed clear, the failing forms of specimens transformation from ductile failure to brittle failure. The bigger spacing of stirrups and the thicker concrete cover made the damage of core concrete get more serious.

(2) As the increasing rate of corroded stirrups, concrete cover is getting damaged more and gradually peering off, the devote to whole bearing capacity of specimen is weaken. The compressive strain of protective layer of non-corrosion stirrups of specimen achieving the peak load occurred in degeneration of bearing capacity. The non-corrosion stirrups of specimen occurred before ultimate bearing capacity, and its compressive strain quickly decreasing before peak load. Is shows that the concrete cover has partly or wholly invalid before the corrosion specimen achieved to the ultimate bearing capacity.

(3) The rate of corrosion stirrups and the characteristic value of stirrups and the damage of concrete cover are the factors which affected the stress-strain curve and parameters of constrained concrete with corroded stirrups. The damage degree get bigger, the initial stage of the curve concaved obviously. Slope, peak load, initial elastic modulus, secant modulus of the peak point of both the increase stage and decrease stage as the increase in losing the rate of maximum weight reduction, as the increase in characteristic value of stirrups increase.

\section{Acknowledgments}

This outcome has been achieved with the financial support of the Natural Science Fund of Shaanxi Province (Project No. 2017JM5045, Name: Study on seismic behavior of corroded reinforced concrete columns) and the National Youth Science Fund of China (Project No. 51408483, Name: The shear performance research on corroded reinforced concrete column). 


\section{Reference}

[1] ANSI/ASCE3-91, Standard for the Structural Design of Composite Slabs[S].

[2] Liu Xila. Fundamental research on safety and durability of major structures in Civil and Hydraulic engineering[J]. China Civil Engineering Journal, 2001,34(6):1 4.

[3] Shi Qingxuan, Li Xiaojian, Niu Ditao, Yang Yadong. Experimental study of bearing capacity of corroded reinforced concrete eccentric compressive members[J]. Industrial Construction, 2001,31(5):4 17.

[4] Jiang Fengchang, Zhu Cimian. Analysis of buckling behavior of longitudinal bars effected by stirrup corrosion in concrete columns[J]. Journal of Southerast Unicersity(Natural Science Edition), 2008, Vol.38(2):279 282.

[5] Jiang Fengchang, Zhu Cimian, Xue Jiansheng,Fu Jian. Experiments and application of buckling nominal constitutive relations of corroded reinforcements[J]. Journal of Southerast Unicersity(Natural Science Edition), 2010, Vol.40(4):816 821.

[6] Lu Xuebin. Buckling property of corroded steel rebar and its influences on reinforced concrete column sectional strength[D]. Master's thesis of Tongji University,2007.

[7] Bazant. Physical model for steel corrosion in concrete sea structures-Application[J]. Journal of the Structural Division, 1979(6):1155 1166.

[8] Bazant. Physical model for steel corrosion in concrete sea structures-Theory[J]. Journal of the Structural Division, 1979(6):1137 1153.

[9] Cabrera. Deterioration of concrete due to reinforcement steel corrosion[J].Cement and Concrete Composites, 1996(18):47 59.

[10] Luo Linglong, Guo Zhenhai. Mechanism and the calculation of the stress-strain curve of restraint concrete by stirrups[R]. Experimental study on concrete mechanics performance, Science research report of Tsinghua university seismic antiknock engineering laboratory, Set 6,1996.

[11] Xiao Jianzhuang. Experimental investigation on complete stress-strain curve of recycled concrete under uniaxial loading[J]. Journal of Tongji Unicersity(Natural Science Edition), 2007,35(11):1445 1449.

[12] Hui Yunling. Assessment and predicted experimental study on corrosive degree of reinforcement in concrete structures[J]. Industrial Construction,1991,27(6): 6 9. 